\title{
O CAMPO DOS ECONOMISTAS FRANCESES NO FIM DOS ANOS 90: LUTAS DE FRONTEIRA, AUTONOMIA E ESTRUTURA
}

Frédéric Lebaron

Na França, durante os anos 90, diferentes índices atestam a "influência" cada vez maior dos economistas. Uma revista de economia, Le Nouvel Économiste, criou, em 1993, um prêmio para recompensar os melhores economistas franceses do ano. Durante a crise social de 1995, os economistas empenharam-se fortemente em lutas em torno das políticas econômica e social e do Plano J uppé, em particular na redação de diferentes petições de apoio ao governo ou aos grevistas, ou tomando posição, de modo crítico, sobre a política econômica implementada (Duval et alii 1998). Em várias ocasiões, manifestos de economistas foram lançados para apoiar esta ou aquela orientação de política econômica, e os economistas viram, incessantemente, seu papel afirmar-se no debate público, quando menos através da proliferação de crônicas econômicas na imprensa ou no rádio. Em 1997, foi criado pelo primeiro-ministro, por sugestão de um economista de sua equipe, um Conseil d'Analyse Économique baseado no modelo do Council of Economic Advisers americano (Coats 1993:611-615), e os mais renomados economistas franceses foram convidados a tomar parte nele. Em junho de 2000, um prêmio para o melhor economista com menos de 40 anos foi pela primeira vez concedido pelo Cercle des Économistes e pelo jornal Le Monde.

Durante todo esse período, os debates sobre a "profissão" ganharam visibilidade - recentemente, o lançamento, por um grupo de estudantes, de uma petição hostil aos excessos de formalização no ensino foi objeto de um longo artigo no Le Monde. Tal envolvimento e influência crescentes poderiam ser comprovados com vários outros indícios, que vão da escalada da economia no ensino das escolas de elite até a "composi ção por economistas" das equipes e comissões ministeriais, passando pelas transformações na escolaridade dos dirigentes de empresas e de altos funcionários e, de modo mais abrangente, no peso da escolarização em ciência econômica (cf. Lebaron 1996). Tudo isso incita a uma interrogação acerca da 
natureza dessa "profissão", sua organização social, o caráter das questões que a perpassam. Longe de constituir um simples caso exemplar para uma sociologia geral das profissões, o universo dos economistas suscita um certo número de problemas teóricos e metodológicos que, certamente, se apresentam em graus variados no estudo de toda "profissão", mas que aqui são "radicalizados".

Muitas incompreensões e erros no uso dos termos "ciência econômica" e "economistas" estão, com efeito, ligados ao fato de estes constituírem sempre objeto de disputa, e não "identidades profissionais" completamente formalizadas e estabilizadas. O mundo dos economistas, na França como em outros lugares, é muito mais diferenciado e heterogêneo do que freqüentemente se pensa, inclusive nos trabalhos que versam sobre a "profissionalização" dos economistas (Coats 1993). A noção de campo, por sua vez, permite evitar as visões cristalizadas do que é um "economista" e as definições a priori daquilo que é a "profissão" de economista, suas normas específicas, seus hábitos etc. ${ }^{1}$. As definições de economista e de ciência econômica são objeto de disputa no seio de um espaço social particular, que tem suas leis, sua lógica, suas relações de força e suas oposições próprias. Quais são as propriedades desse universo social específico? Em particular, como são definidas e mantidas suas fronteiras? Qual é seu grau de autonomia e em relação a que universos? Qual é a estrutura interna desse campo? Tentarei aqui responder a estas questões, isto é, caracterizar o lugar das lutas de classificação, determinar a natureza e o grau de autonomia desse campo, e mostrar sua estrutura interna.

\section{As lutas de fronteira}

A questão das fronteiras do campo é, a um só tempo, um problema prático de pesquisa estatística - qual é a população de referência? qual é a amostra considerada? - e uma questão teórica: quem está dentro e quem está fora do campo? O que significa estar no interior ou fora desse campo particular que é o dos economistas? M elhor que partir das fronteiras oficiais de um grupo ou de uma "profissão" (fronteiras que podem ser determinadas de direito, de modo burocrático etc., que são mais ou menos codificadas e padronizadas), trata-se de colocar em primeiro plano o investimento no "sentido do jogo" dos agentes sociais que aí encontram uma forma de "interesse" ou, mais precisamente, de illusio. As fronteiras de um universo social não se reduzem às fronteiras formais ou institucionais, pois elas correspondem, em primeiro lugar, aos limites do efeito de 
campo, ou seja, aos limites da illusio compartilhada pelos atores do campo. No caso dos economistas, não existe em parte alguma codificação e controle estrito da noção de "economista" (Klamer e Colander 1990), e o efeito de campo limita-se ao conjunto dos agentes que participam do jogo em que consiste a tentativa de produzir um discurso econômico científico, o acreditar na possibilidade de uma "ciência econômica" ou, ao menos, de uma disciplina econômica.

Seria um erro considerar como pertencentes ao campo apenas os economistas acadêmicos, dado eles estarem credenciados pelas instituições acadêmicas com a posse do conhecimento econômico "puro" ou "teórico". Para a maior parte dos historiadores e sociólogos da "profissão" (Coats 1993; Whitley 1984), os economistas teóricos definem mais sutilmente o núcleo duro da profissão, situando-se os demais em sua periferia (cuja extensão e limites, todavia, raramente são discutidos). Desde a revolução marginalista dos anos 1870, ter-se-ia constituído, em torno da teoria neoclássica, um grupo de profissionais da economia ligado a um modelo de atividade científica "moderna", baseado na oposição entre ciência pura e valores, cujo trabalho consistiu em unificar, padronizar e racionalizar as práticas e os hábitos dos especialistas. Teríamos assistido assim a um processo clássico de especialização disciplinar em torno dos guardiães da teoria pura, erigida em instância última de consagração (Caro 1983). Uma vez realizada a primeira etapa de definição profissional, a "profissão" teria começado a estender-se além da esfera inicial e, paralelamente, as idéias econômicas não teriam cessado de se difundir no restante do sistema social (Hall 1989; Colander e Coats 1990).

Se considerarmos o universo dos economistas como um campo, não há, de fato, razão para privilegiar a priori uma definição social, ainda que a posse da "teoria econômica" esteja, de fato, freqüentemente, associada ao controle da definição última da "cientificidade" nesse campo. As lutas de classificação entre os economistas remetem a diferentes formas de autoridade, de prestígio, de poder social etc., que estão em incessante concorrência. Tais lutas têm por objeto a definição do "verdadeiro economista", a determinação dos seus atributos legítimos, das qualificações e das técnicas associadas à própria noção. As instâncias de formação dos economistas, assim como os diferentes pontos de contato entre a "profissão" e o restante do mundo social (imprensa, mídia, publicações, colóquios públicos etc.), estão perpassados por essas lutas. Pode-se ser tachado de economista "teórico" em nome da "realidade" e, inversamente, como economista "prático" em nome da ciência; ambas as formas de exclusão coexistem no campo. 
À questão "o que é um economista?", um economista da Direction de la Prévision² do Ministério da Fazenda (que é também doutorando em macroeconomia na Universidade de Paris I) respondeu: "como todo mundo, eu chamo economistas as pessoas que se parecem com aquelas que trabalham ao redor de mim como economistas" (Entrevista, 1993). Esta definição, totalmente genérica, sugere a importância da proximidade e da distância na qualificação de um agente como "economista". Outro economista do Ministério da Fazenda contestou, na mesma época, o fato de se chamar "economista" à maior parte dos membros recém-nomeados ${ }^{3}$ do Conseil de Politique Monétaire do Banque de France, "conservando" nessa categoria apenas um jornalista que, então, fazia parte de uma comissão formada por especialistas em análise de conjuntura [conjoncturistes] no seio de sua própria instituição. No Ministério da Fazenda, um econometrista, que tivera funções de conselheiro de política econômica, qualificou como "economista" o diretor do Tesouro, futuro presidente do Banque de France e depois indicado para a direção do Banco Central europeu, J ean-Claude Trichet, sendo contestado por muitos economistas acadêmicos: licenciado em ciências econômicas, mas enarque* e inspetor de finanças, esse alto funcionário fez toda a sua carreira na administração financeira. Durante a campanha presidencial de 1995, um escritor que fez fortuna escrevendo best-sellers, Paul-Loup Sulitzer, apresentou-se na televisão como "economista", embora sua competência econômica reconhecida residisse principalmente, com toda certeza, em ter escrito um romance intitulado M oney4. Um trabal ho sobre as designações de economista no Who's Who in France revela a extrema diversidade das posições profissionais, das propriedades sociais e da escolaridade daqueles que se autodenominam "economistas" (Lebaron 1996). Enfim, a prova mais cabal deste ponto advém, talvez, do fato de que, ao longo desta pesquisa sociológica sobre os economistas franceses, o autor destas linhas tenha sido, com freqüência, considerado como um "economista" pelos sociólogos e, após várias publicações, por certos economistas.

Outro problema de fronteira está na noção de "economista francês". Seria legítimo isolar um subcampo do campo mundial dos economistas, no contexto atual de internacionalização que também afeta essa profissão?5 Certos economistas oferecem uma resposta - positiva - a essa questão nas discussões profissionais que têm lugar, principalmente, entre "acadêmicos" a propósito das diferenças entre a profissão econômica na

* N. T. - Enarque: aluno ou ex-aluno da Escola Nacional de Administração (ENA). 
Europa e nos Estados Unidos (por exemplo na revista alemã Kyklos). Nos diferentes países europeus, a economia assume formas específicas, ligadas à importância relativa dos financiamentos e do emprego público, das carreiras político-administrativas etc., o que está associado a tomadas de posição freqüentemente mais "intervencionistas", mais "keynesianas" (Frey e Eichenberger 1992). Uma parte importante da pesquisa econômica parece bastante internacionalizada, mas trata-se, na verdade, de um setor específico da produção em ciência econômica, concernente sobretudo aos pesquisadores que efetivamente publicam em revistas internacionais - pouco numerosos, mesmo entre os universitários que controlam as carreiras acadêmicas nacionais no seio do Conseil National des Universités (CNU) 6 (Combes e Linnemer 1999) - , fazem carreira internacional (passando pelo Massachusetts Institute of Technology (MIT) ou Fundo M onetário Internacional (FMI), ou pelo Banco M undial) ou, ainda, os diferentes importadores, sem dúvida numerosos, de tecnologias de política econômica ou de análise financeira americanas (J obert e Théret 1994; Drake 1993; Kelsey 1995).

Se levarmos em conta o conjunto do campo francês, observaremos que as esferas políticas e midiáticas funcionam como fontes de prestígio especificamente nacional. A criação do Conseil d'Analyse Économique, do prêmio de "melhor economista francês" e a existência de associações nacionais (ao menos quatro grandes associações generalistas concorrem para a definição da identidade social do economista: a Association Française de Science Économique (AFSE), a Association Nationale des Docteurs en Science Économique, a Association Française des Économistes d'Entreprise e a Société d'Économie Politique) e até mesmo de organizações como o Conseil National des Universités e o Centre National de la Recherche Scientifique (CNRS) (instâncias nacionais de controle e direção das carreiras), apontam para uma especificidade que justifica o isolamento, ao menos em uma primeira análise, do campo dos economistas franceses.

\section{A autonomia do campo da economia}

$\mathrm{Na}$ ausência de um método simples para determinar se um campo de produção cultural, em particular um campo científico, é mais ou menos autônomo, e em relação a que outros campos sociais, podemos pensar que as melhores respostas à questão da autonomia estão no conjunto de argumentos empíricos que se pode fornecer em apoio a cada uma das 
hipóteses presentes 7 . O campo dos economistas parece, à primeira vista, dotado de traços característicos de uma forte autonomia: uma linguagem muitas vezes extremamente esotérica, bastante distanciada do senso comum; procedimentos sofisticados de integração dos jovens iniciantes; normas técnicas próprias; existência de tradições intelectuais, de correntes, de categorias de classificação que Ihe são específicas ("neoclássicas", "pós-keynesiana", "nova macroeconomia clássica", "marxista", "neo-ricardiana", "convencionalista"8 etc.); critérios próprios de avaliação e um sistema de gratificação com o prêmio Nobel (Roux e Soulié 1991:VII) no topo e diversas etapas intermediárias. Esse campo é integrado cientificamente, como mostra a unificação dos cursus de economia em torno de três pólos: microeconomia, macroeconomia e econometria. $\mathrm{O}$ predomínio de critérios internos de avaliação é o resultado de um processo de autonomização comparável àquele que se produziu na física, na química, na biologia etc., a partir da "revolução científica" dos séculos XVI e XVII (Shapin e Shaffer 1993). Aliás, na França, no início dos anos 90, organizou-se um colóquio sobre o tema: “A economia não se tornou uma ciência dura?" (D’Autume e Cartelier 1995). Vários participantes responderam positivamente, e hoje parece existir no país, entre os economistas (ao menos entre professores universitários e pesquisadores), um consenso em torno da representação da economia como uma ciência "quase-natural". Somente economistas de prestígio, e parcialmente afastados das lutas profissionais (como Edmond Malinvaud), podem perguntar-se, de modo provocativo, "por que os economistas não fazem descobertas" (Malinvaud 1996).

No entanto, vários fatos vêm contradizer ou dificultar a representação dominante que considera a economia uma ciência autônoma. É, antes de tudo, relativamente fácil questionar a predominância de critérios internos no campo dos economistas. A criação do prêmio do Nouvel Économiste e a instituição do Conseil d'A nalyse Économique são, no extremo oposto, exemplos bastante concretos da intromissão dos poderes políticos e midiáticos no interior do campo. A economia é a única disciplina científica cuja produção e os produtores os jornais e os políticos têm o direito de avaliar, ao menos indiretamente. (O próprio Prêmio Nobel foi criado em 1968 para o terceiro centenário do Banco Real da Suécia, um poder econômico no mínimo engajado.) Uma parte dos economistas neoclássicos dos Estados Unidos considera, aliás, uma consagração a nomeação para postos de responsabilidade econômica de primeiro plano: economistachefe do Banco M undial, depois secretário do Tesouro (Larry Summers), ou deputy managing director do FMI (Stanley Fisher), por exemplo. A 
hipótese de que o campo é fortemente autônomo é desenvolvida por vários professores universitários e pesquisadores, recrutados e avaliados por seus pares, publicando em revistas segundo critérios formais de avaliação. Tal hipótese ignora a presença no campo de outros tipos de economistas, que trabalham no mundo empresarial ou administrativo e conquistaram parte de sua notoriedade nesses espaços particulares. Ora, esses economistas não são nem recrutados nem avaliados segundo critérios unicamente acadêmicos, ligados apenas à "produção científica". Ao mesmo tempo coexistem diferentes instâncias de consagração, distintas fontes de capital simbólico que, freqüentemente, concorrem entre si e remetem a diferentes definições de economista. Os economistas mais matemáticos são repetidamente criticados pelo fato de serem mais matemáticos do que economistas e não se interessarem por problemas econômicos reais, mas apenas por enigmas (puzzles) lógicos ou formais. É preciso, também, lembrar as importantes flutuações nos processos de recrutamento universitário e administrativo em função das mudanças políticas, as lógicas de produção e controle (e até mesmo de censura) das análises econômicas nas organizações burocráticas ${ }^{9}$, econômicas e políticas, e a importância das condições de financiamento da pesquisa no aparecimento histórico e no desenvolvimento dos trabal hos, mesmo quando são percebidos como os mais autônomos ${ }^{10}$. A dependência em relação ao campo político é particularmente forte: o fato de este conceder às "competências econômicas" um lugar central, especialmente desde o século XIX, e a escalada do movimento operário, são manifestações dos múltiplos vínculos que tornam o destino da disciplina indissociável do estado das relações de força no campo político.

Outro argumento favorável à hipótese de forte heteronomia, ligado à expressiva heterogeneidade desse campo, remete ao elevado nível de desacordo e até mesmo de dissenso em seu interior, que pode ser considerado um indicador da fraca integração e da fraca autonomia que o caracterizam. Desde o início dos anos 80 , inúmeras pesquisas realizadas em diferentes países (Estados Unidos, França, Grã-Bretanha etc.) destacaram a importância dos desacordos entre os economistas, tanto sobre questões de política econômica - onde eles são particularmente fortes quanto a respeito de questões teóricas ou até mesmo empíricas (determinação de certos coeficientes ou parâmetros) - onde os desacordos menos acentuados são, entretanto, importantes (ver, esp., Bobe e Etchegoyen 1981; Frey e Eichenberger 1992; Fuchs et alii 1998). 


\section{A estrutura do campo}

Um último argumento em favor da hipótese de fraca autonomia do campo dos economistas pode ser encontrado na sua própria estrutura. Com efeito, um campo muito autônomo deve, também, logicamente, caracterizarse por uma estrutura muito diferenciada com relação àquela do espaço social global que o envolve e, em particular, em relação ao campo do poder. É o contrário o que se observa no caso dos economistas franceses. O campo dos economistas pode ser descrito como um prisma onde o conjunto do campo do poder se refrata de modo muito fiel (Lebaron 1997). Para pôr em evidência sua estrutura, recorremos aos métodos de análise geométrica dos dados - neste caso, à análise das correspondências múltiplas - , assim como a uma série de entrevistas (cerca de cinqüenta) e a observações diretas realizadas em diversas ocasiões (colóquios, conferências, defesas de teses etc.).

A primeira oposição que organiza o campo corresponde estritamente ao volume de capital científico global detido pelos economistas. Ela os distingue, em primeiro lugar, conforme a relação que mantêm com o mundo das universidades ("não universitários" versus a "universidade de província"); em segundo lugar, conforme o tipo de formação superior que possuem (Politécnica, ENSAE, a ausência de diploma universitário em economia versus a agrégation* em ciências econômicas) e, por último, conforme o local de residência (os bairros burgueses de Paris versus a residência no interior). Uma parte importante da variância do primeiro eixo está na oposição social multiforme que se estabeleceu, na França, entre Paris e o interior, entre as grandes escolas e a universidade, e entre o mundo empresarial, da administração e da política e o mundo acadêmico. A projeção da origem social como elemento suplementar confirma esta interpretação: em um pólo encontram-se os economistas oriundos da burguesia e da aristocracia; no outro, aqueles procedentes das classes populares e médias ${ }^{11}$.

A segunda oposição corresponde também a um princípio que estrutura o campo do poder e o espaço das classes dominantes, pois distingue os poderes políticos e econômicos dos poderes intelectuais e técnicos. Encontram-se, em um pólo, economistas cuja autoridade depende primordialmente de sua obra pessoal (como Edmond Malinvaud, professor no Collège de France e fundador da escola francesa dos “equilíbrios a pre-

\footnotetext{
* N. T. - Agrégation: sistema de admissão, por concurso, de professores em liceus e faculdades na França.
} 
ços fixos", ou Robert Boyer, orientador de pesquisas no CNRS e orientador de estudos na École des Hautes Études en Sciences Sociales (EHESS), um dos fundadores da "escola da regulação" 12). No outro, estão os economistas mais ligados aos poderes econômicos e políticos (antigos ou atuais ministros, dirigentes de empresas, economistas de bancos e de instituições financeiras etc.). $O$ vínculo com as empresas e com o campo político stricto sensu (isto é, a arena eleitoral) e a distância do mundo universitário e da administração correspondem à ocupação de uma posição vinculada ao exercício de uma forma de poder em parte independente da produção de teorias ou de discursos profissionais específicos. A taxa de citação no Social Science Citation Index (utilizada aqui de modo relativamente "grosseiro", pois fizemos a soma das citações dos economistas durante um ano) opõe os detentores de uma legitimidade principalmente "interna" (obtida junto aos pares) a uma legitimidade "externa", ligada às demandas sociais múltiplas (políticas, gerenciais, midiáticas...), de que a economia é objeto, e da qual a presença no Who's Who in France é um indicador. Aliás, até mesmo os produtores mais "autônomos" são, através da administração, de contratos de pesquisa etc., dependentes de forças externas ${ }^{13}$.

Uma terceira oposição remete ao grau de envolvimento dos economistas nas instituições acadêmicas ou burocráticas nacionais e, inversamente, com o mundo anglo-saxão (americano). Ela opõe os agentes que estudaram nos Estados Unidos, e são ou pesquisadores fixados na França, como J ean Tirole (Toulouse, MIT), ou homens políticos cuja formação superior ocorreu nos Estados Unidos, de um lado, aos economistas mais diretamente envolvidos com a vida científica e intelectual nacional, membros de associações como a Association Française de Science Économique (AFSE) ou a Société d'Économie Politique, de outro14.

A estrutura do campo dos economistas franceses corresponde, portanto, a uma estrutura encontrada no estudo do campo do poder (Bourdieu 1979; 1989). Ela distingue não apenas o volume global de capital científico, mas também duas formas dominantes desse capital entre os economistas (político e econômico, por um lado; intelectual e técnico, por outro) e, em um terceiro eixo, os economistas inscritos em um espaço internacional e aqueles mais nacionais. Restaria estudar, é claro, a maneira pela qual essa estrutura se constituiu historicamente, e seu caráter especificamente "francês".

Às três questões apresentadas inicialmente, a pesquisa sobre o campo dos economistas franceses dos anos 90 permitiu fornecer elementos coerentes de resposta. A definição de pertencimento a um campo apare- 
ce tanto mais como objeto de disputas essenciais quanto este campo se apresenta como pouco autonomizado em relação aos poderes externos (notadamente, econômicos e políticos). Do mesmo modo, sua estrutura interna tende a apresentar fortes analogias com a estrutura do espaço social mais amplo no qual está inscrito. Resulta daí que a noção de "profissão", freqüentemente invocada pelos próprios economistas para descrever seu universo, é aqui particularmente enganadora, pois tende a dar uma visão integrada, unificada e autônoma de um espaço social heterogêneo, fragmentado e heterônomo.

\section{Nota Metodológica}

A pesquisa de campo foi realizada, principalmente, entre 1992 e 1996. Ela consistiu em observações diretas (em colóquios, seminários, defesas de tese etc.), em uma série de entrevistas (em torno de cinqüenta) com economistas representativos dos diferentes pólos, na exploração de dados estatísticos já existentes ou coletados (pesquisa por questionário junto a estudantes do ENSAE, pesquisas "prosopográficas" sobre, por exemplo, os economistas presentes no Who's Who em 1969-70, 1989-90, 1994-95, sobre os autores das Mélanges Économiques. Essais en I'Honneur d'Edmond Malinvaud, ou, ainda, sobre os economistas que se posicionaram publicamente quando da crise social de novembro/dezembro de 1995).

Uma pesquisa sobre a totalidade do campo dos economistas franceses em meados dos anos 90 foi feita em 1997. A determinação de uma população "representativa" do campo foi particularmente delicada por conta da multiplicidade dos princípios de definição concorrentes. Optei por respeitar essa multiplicidade, construindo uma amostra razoável, representativa do conjunto dos agentes eficientes, a partir de fontes diversas: anuários de associações, dicionários e obras biográficas, livros coletivos, documentos públicos, informações diretas etc. A amostra considerada na análise das correspondências múltiplas, sobre a qual se baseia o texto, conta com 220 economistas. Os economistas do interior, os maîtres de conférences e os professores universitários não titulares aí estão, notadamente, sub-representados (se compararmos aos dados, esparsos, que disponho sobre o conjunto do campo).

Diferentes grupos de variáveis foram construídos: 
Propriedades sociais: sexo, idade, profissão do pai, presença no Who's Who 1994-95, família no Bottin M ondain em 1986, local de residência, local de trabalho, pertencimento a uma corporação estatal.

Trajetória e títulos acadêmicos: passagem por uma grande escola, diploma universitário em economia, diploma científico, diploma em ciências humanas, diploma em ciências políticas, diploma em gestão, diploma ou formação nos Estados Unidos.

Posição e trajetória profissional: instituição universitária, cargo universitário, instituição administrativa, cargo administrativo, setor econômico da empresa, cargo na empresa, responsabilidade política, crônica midiática, trajetória profissional, presença no CNU.

Filiação a associações: Association Française de Science Économique (AFSE), Comitê Diretor da AFSE, Société d'Économie Politique (SEP), Association $\mathrm{N}$ ationale des Docteurs en Science Économique et en Gestion (ANDESE), Cercle des Économistes, A ppel des Économistes pour Sortir de la Pensée Unique, Répertoire des Économistes Non-Conformistes (cf. Weiller e Carrier 1994), associação internacional generalista, associação internacional específica, associação financeira (Association d'Économie Financière (AEF) e A ssociation Française de Finance (AFFI)).

Notoriedade: distinção científica, citações no Social Science Citation Index (SSCI), artigos no Le Monde em 1995.

Tomadas de posição científica: campo de especialização, corrente, formalização matemática, editor.

Tomadas de posição política: tomada de posição pública em dezembro de 1995, militância política notória, militância política passada.

A "análise das correspondências múltiplas" (ACM) permite explorar a estrutura das associações entre as diferentes variáveis consideradas. $O$ conjunto de variáveis ativas da análise foi escolhido para explorar as propriedades de trajetória e de posição dos agentes. Em uma segunda fase, projetei as variáveis de tomadas de posição como elementos suplementares, o que significa considerá-las como variáveis "explicadas" pela estrutura (cf. Lebart et alii 1995:122-123), conforme o vocabulário da regressão. A ACM permite, assim, combinar descrição exploratória aprofundada com hipóteses "explicativas".

Vinte e sete variáveis ativas, ou seja, 75 modalidades, foram consideradas entre as variáveis de trajetória social e escolaridade e de posição no campo. Elas foram escolhidas em função da qualidade diferente dos dados e de sua redundância eventual. 
Propriedades sociais: sexo (2), Who's Who 1994-95 (2), Bottin Mondain (2), local de residência (5 modalidades: Paris 5ème, 8ème, 16ème, Neuilly/outros bairros de Paris/outra região parisiense/interior/NSP).

Trajetória e títulos acadêmicos: diploma em ciências econômicas (4 modalidades: sem/agrégation/doutorado/DES e menos), Politécnica (2), ENSAE (2), Ponts* (2), HEC (2), IEP de Paris (2), outro diploma científico (2), diploma em letras, direito, ciências políticas (2), diploma em gestão (2), diploma ou formação nos Estados Unidos (2).

Posição e trajetória profissional: instituição universitária (10 modalidades: sem/Panthéon (Paris I e Paris II)/Paris IX (Dauphine)/Paris X (Nanterre)/ outros bairros de Paris e região parisiense/universidade do interior/CNRS/EHESS/IEP e CNAM/outra grande escola), instituição administrativa (6 modalidades: sem/Comissariado de Planejamento e organismos afins/instituições internacionais/INSEE e DP/Banque de France e instituições financeiras públicas/outras), setor econômico empresarial (3 modalidades: sem objeto/indústria, organizações profissionais, conseIho/banco, seguros, finanças), cronista midiático (2), responsabilidades políticas (3 modalidades: sem/el eito local (até deputado)/eleito ou dirigente nacional), membro do comitê diretor da AFSE (2).

Filiação a associações: AFSE (2), ANDESE (2), SEP (2) Cercle des Économistes (2), Appel des Économistes pour Sortir de la Pensée Unique (2).

Notoriedade: citações no Social Science Citation Index (3 modalidades: 0/1 a 10/mais de 10), artigos no Le Monde em 1995 (3 modalidades: sem/autor de artigo/tema de artigo).

Foram projetados como elementos suplementares:

Posição no campo (dados complementares): funcionário público (3 modalidades: sem/administrador ou inspetor geral do INSEE/alta burocracia), cargo universitário (3 modalidades: sem objeto/titular (maîtres de conférences ou professor)/professor-associado), cargo administrativo (4 modalidades: sem objeto/diretor ou subdiretor/outro funcionário/conselheiro científico), cargo na empresa (4 modalidades: sem tema/dirigente executivo superior/diretor de estudos econômicos/consultor), trajetória profissional ( 7 modalidades: somente universidade/somente administração/empresa (e universidade ou administração)/administração + universidade/administração +empresa + universidade/universidade + política/outra), profissão do

\footnotetext{
* N. T. - Trata-se da Escola de Pontes e Vias Públicas, importante instituição de ensino de engenharia.
} 
pai (13 modalidades: NSP/empregado, operário/executivo médio/agricultor, artesão e comerciante/professor, profissão intelectual/executivo superior público/executivo superior privado/engenheiro/alto funcionário/oficial/profissão médica/profissão jurídica/patrão, empresário), passagem pela ENS da Rue d'UIm (2), editor principal (10 modalidades: sem/Econômica/PUF/PUF + Econômica/editor generalista/editor militante/La Découverte/editor universitário/editoras universitárias, editoras de instituições científicas/editor administrativo), honras científicas ( 6 modalidades: Prêmio Nobel, medalha CNRS, Collège de France/prêmio ou admissão no Instituto/prêmio acadêmico nacional/prêmio acadêmico internacional/prêmio do Nouvel Économiste/outro prêmio empresarial), passagem por um gabinete ministerial (3 modalidades: sem/gabinete de esquerda/gabinete de direita), menção no L'Économie N on-conformiste en France au XX Siècle, organizado por J . Weiller e B. Carrier (2), membro de uma associação financeira (2), de uma associação internacional (3 modalidades: sem/generalista/especializada), presença no Conseil National des Universités - seção de ciências econômicas - em 1996 (2).

Tomadas de posição científica: campo de especialização (9 modalidades: macroeconomia, política econômica/microeconomia, econometria/moeda, finanças/economia do desenvolvimento e dos países socialistas, economia regional, meio ambiente/economia industrial, gestão/conjuntura/economia internacional/economia do trabalho, economia social/economia geral, história do pensamento), corrente (7 modalidades: NSP/keynesiana/liberal/outra neoclássica/convenções e regulação/marxista/outra heterodoxa), formalização (3 modalidades: + / =/ -).

Tomadas de posição política: tomada de posição em dezembro de 1995 (5 modalidades: sem/A pelo Rosa/apelo de apoio às greves e apoio/Esprit e posições intermediárias/A pelo Debonneuil e condenação das greves), militância política notória (4 modalidades: sem/esquerda socialista/ esquerda não socialista/direita), militância passada (3 modalidades: sem/ esquerda/extrema-esquerda).

\section{Os gráficos}

Os gráficos aqui reproduzidos permitem visualizar: a) o espaço das posições através da projeção sobre o primeiro plano principal (1-2) dos pontos médios das modalidades ativas cuja contribuição à formação de um dos dois primeiros eixos é superior a $2 \%$ (Gráfico 1 ); b) o espaço das tomadas de posição através da projeção sobre o primeiro plano principal dos pon- 
tos médios dos fatores estruturantes: tomada de posição em dezembro de 1995, militância política notória presente e passada, corrente, campo de especialização, editor (Gráfico 2) e c) a nuvem dos pontos representando a concentração dos indivíduos sobre a base dos dois precedentes. Os gráficos foram realizados com o programa EyeLID-216 e o ACM com o programa ADDAD.

Recebido em 10 de fevereiro de 2000

A provado em 29 de junho de 2000

Tradução: Eloisa Araújo Ribeiro e J oão Luiz Ribeiro

Frédéric Lebaron é professor de sociologia na Universidade de Picardie-J ules Vernes e pesquisador no Centre de Sociologie Européenne (Collège de France, École des Hautes Études en Sciences Sociales, Centre National de la Recherche Scientifique), especializado em sociologia econômica e metodologia. Publicou La Croyance Économique (2000), além de artigos em revistas especializadas. 
Gráfico 1. 0 espaço das posições sociais

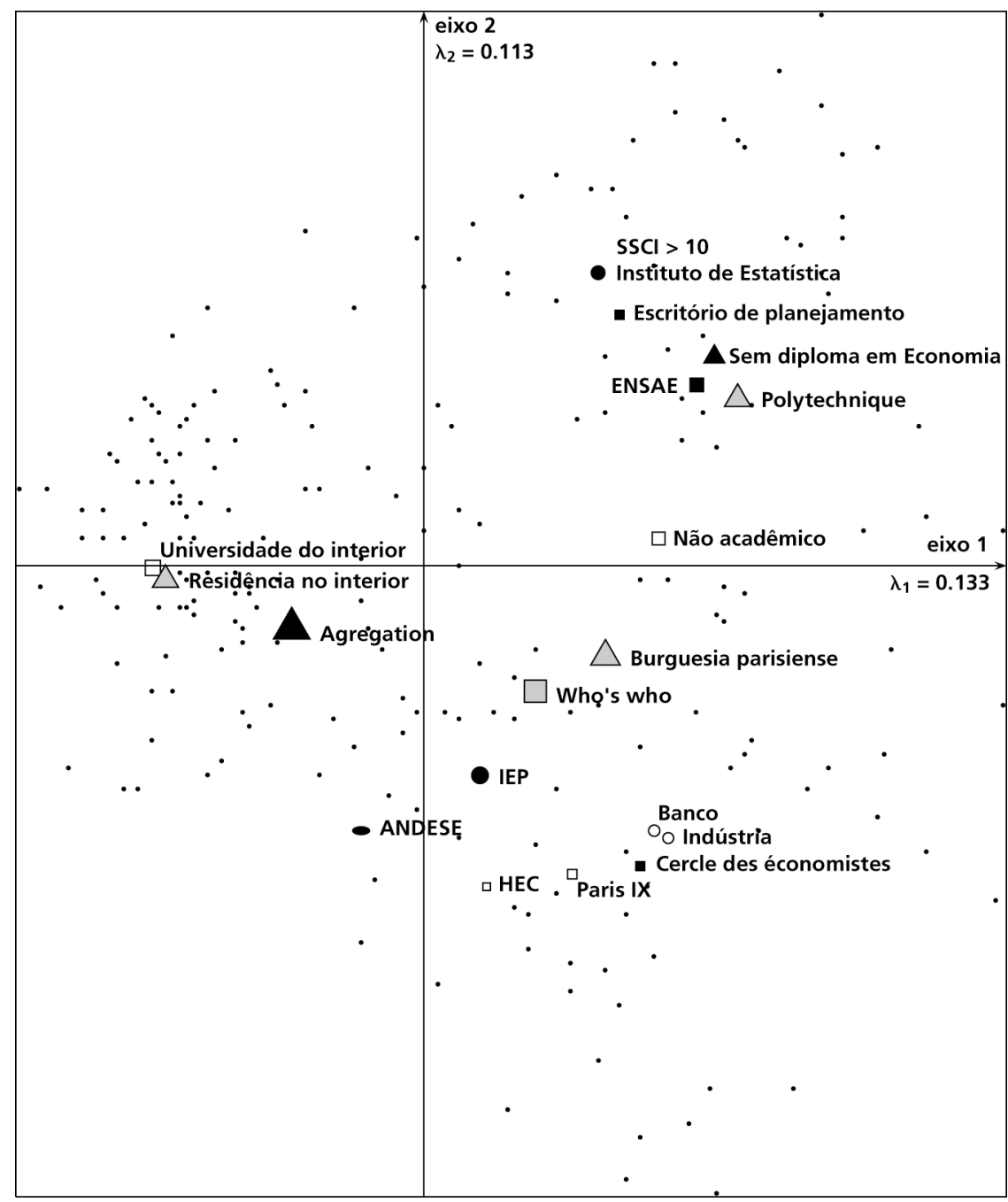


Gráfico 2. 0 espaço das tomadas de posição política

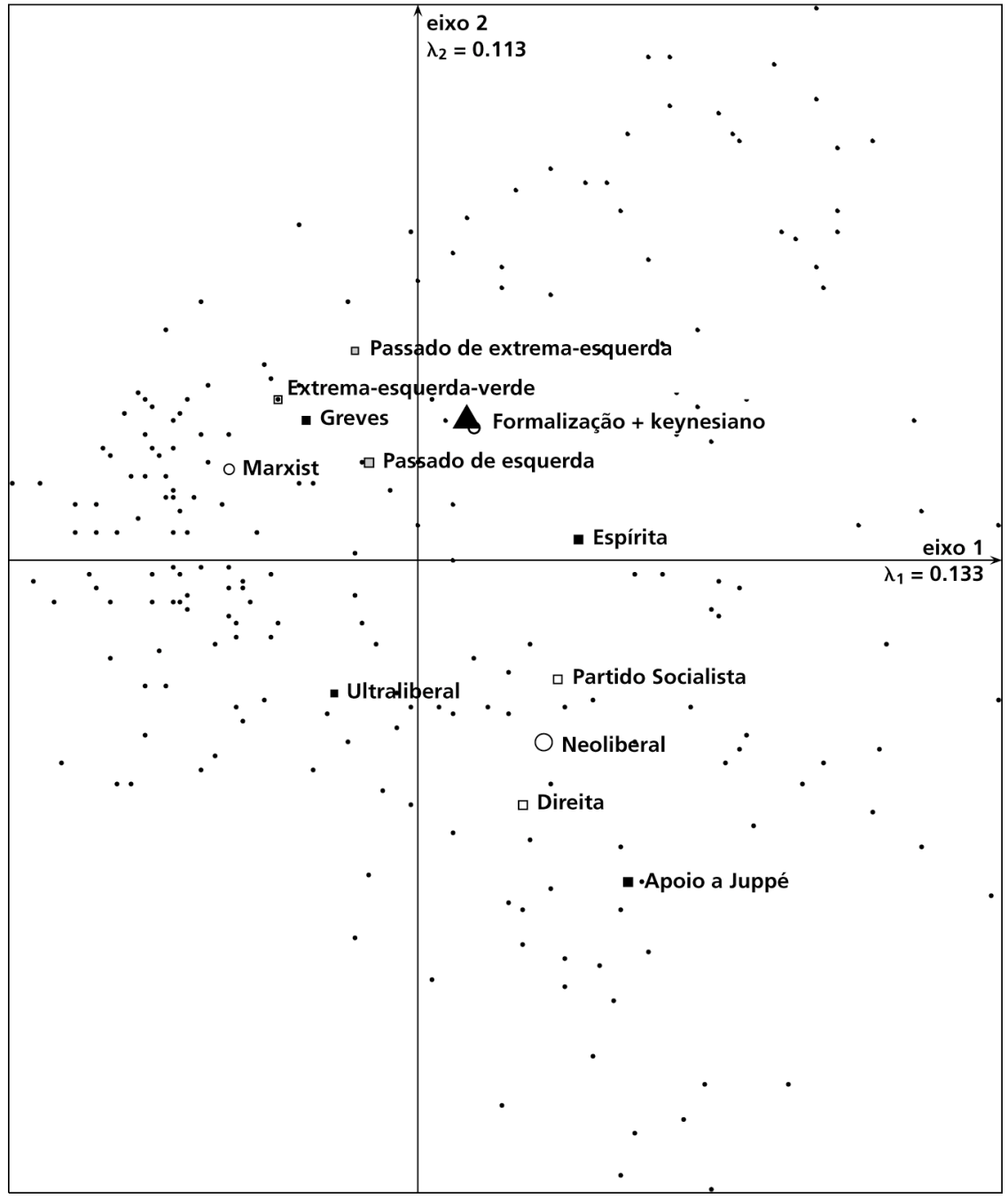




\section{Notas}

1 Sobre os perigos dessa categoria nativa, cf. Bourdieu (1992:211-215).

2 A "DP" é um dos principais organismos estatais onde é produzida, difundida e retraduzida uma ciência econômica voltada para a ação pública. Embora ela fosse relativamente "pluralista" nos anos 70 , seu caráter "ortodoxo" afirmouse nos anos 80 .

3 Em 1994, o Banque de France tornou-se "independente", a fim de satisfazer às condições do Tratado de Maastricht, na perspectiva de criação de uma moeda européia única. Um “Conselho de Política Monetária” composto de nove "sábios" foi nomeado naquela ocasião.

4 Autor de romances para o grande público que fizeram grande sucesso nacional e internacional nos anos 80, Paul-Loup Sulitzer especializou-se em histórias de grandes managers e heróis da economia.

5 A propósito, ver Coats (1997).

6 O Conseil National des Universités é a instância central (nacional) de avaliação dos professores-pesquisadores. Ele fornece "qualificações" em diferentes níveis de graduação (mestre de conferências, professor) que possibilitam a candidatura a uma universidade, sendo, então, avaliados por uma "comissão de especialistas" composta, a um só tempo, por professores universitários do país e do exterior.

7 Para uma justificação desse tipo de metodologia, cf. Simiand (1932).

8 A Escola das Convenções, constituída nos anos 80 em torno de Olivier Favereau, André Orléan, Robert Salais, Laurent Thévenot, desenvolve uma nova variante de economia institucionalista, centrada no problema da "coordenação" das ações econômicas. Ela inscreve-se no quadro do individualismo metodológico, mas propõe uma versão ampliada a formas de racionalidade que o "modelopadrão" não leva em conta.

9 Sobre a Direção da Previsão e os órgãos de estudos “independentes”, cf. J obert e Théret (1994).

10 As flutuações dos conteúdos das pesquisas em função dos financiamentos públicos e privados foram, até agora, pouco estudadas em economia, por tratar-se de um tema difícil por razões evidentes de acesso à informação.

11 As variáveis que mais contribuem para a inércia do primeiro eixo $(7,49 \%$ de inércia global, ou seja, um valor próprio de 0,13 e uma taxa modificada de $37,86 \%)$ são a posição universitária $(0,185)$, Politécnica $(0,123)$, o diploma univer- 
sitário em economia $(0,117)$, o local de residência $(0,109)$, a $\operatorname{ENSAE}(0,069)$ e os vínculos com empresas $(0,061)$. No pólo do grande volume de capital, as categorias que contribuem com mais de 0,03 são a Politécnica $(0,096)$, a falta de diploma universitário em economia $(0,065)$, a $\operatorname{ENSAE}(0,057)$ e a residência em bairros burgueses de Paris $(0,039)$ e não universitários $(0,033)$. No outro pólo, encontram-se universidade de província $(0,063)$, residência no interior $(0,062)$ e a agrégation em ciências econômicas $(0,035)$. Sobre as taxas de variância modificadas, ver Rouanet e Le Roux (1993:267).

12 A denominação "Escola da Regulação" agrupa notadamente os trabalhos de Michel Aglietta, Robert Boyer, Alain Lipietz etc. Oriunda de uma variante heterodoxa do marxismo, ela inspira-se, também, na macroeconomia de Kalecki e nos trabalhos da Escola Histórica dos Annales.

${ }^{13}$ As variáveis que mais contribuem para a inércia desse segundo eixo (6,38\% de inércia global, ou seja, um valor próprio de 0,11 e uma taxa modificada de $23,92 \%)$ são os vínculos com as empresas $(0,107)$, a posição universitária $(0,106)$, a posição administrativa $(0,089)$, o número de citações no Social Science Citation Index $(0,087)$, a presença no Who's Who in France $(0,068)$, o diploma universitário em economia $(0,061)$. Do lado dos poderes econômicos e políticos, as modalidades que contribuem com mais de 0,03 para a formação do eixo são: IEP de Paris $(0,048)$, Paris IX-Dauphine $(0,043)$, banco ou instituição financeira $(0,043)$, indústria ou conselho (0,043), "Cercle des Économistes" $(0,042)$, Who's Who in France (0,039), "Association Nationale des Docteurs en Science Économique et en Gestion" (0,039), HEC (0,031). No outro pólo figuram “mais de 10 citações no SSCI" $(0,067)$, falta de diploma universitário em economia $(0,045)$, INSEE-DP $(0,040)$, Politécnico $(0,037)$, ENSAE $(0,033)$.

${ }^{14}$ As variáveis que mais contribuem para a inércia do terceiro eixo (4,83\%, ou seja, um valor próprio de 0,09 e uma taxa modificada de 9,81\%) são a posição universitária $(0,155)$, o pertencimento à $\operatorname{AFSE}(0,108)$, o local de residência $(0,095)$, a passagem pelos Estados Unidos (0,084), o diploma universitário em economia $(0,072)$ e as responsabilidades políticas $(0,070)$. No pólo mais exterior ao espaço nacional, as modalidades que mais contribuem são os estudos nos EUA $(0,073)$, não-pertencimento a AFSE $(0,052)$, o doutorado em ciências econômicas $(0,040)$, CNRS $(0,035)$, um outro diploma em ciências $(0,032)$, um diploma em gestão $(0,031)$, a posição de eleito ou dirigente político nacional $(0,031)$ e de eleito ou dirigente político local $(0,031)$. No pólo mais nacional figuram membros da AFSE $(0,057)$, da Société d'Économie Politique $(0,038)$, da $\operatorname{ENSAE}(0,037)$, do comitê diretor da $\operatorname{AFSE}(0,036)$, do Banque de France $(0,031)$, de bancos e instituições financeiras $(0,030)$.

${ }^{15}$ As análises pós-fatoriais e a exploração de subnuvens e de nuvens derivadas são facilmente realizadas com a ajuda do programa EyeLid. EyeLid foi desenvolvido por Bernard, Rouanet e Baldy, do Grupo Matemáticas e Psicologia, Université René Descartes. Ver Bernard J .M., Baldy R., Rouanet H. (1988), “The Language for Interrogating Data LID". In: Diday (ed.), Data Analysis and Informatics V, pp. 461-468; Elsevier, North Holland; e Bernard J.M., Le Roux B., 
Rouanet H. \& Schiltz M.A. (1989), “Analyse des Données Multidimensionnelles par le Langage d'Interrogation des Données LID: au delà de I'A nalyse des Correspondances". Bulletin de M éthodologie Sociologique, 3:3-46.

\section{Referências bibliográficas}

BOBE, B. e ETCHEGOYEN, A. 1981. Économistes en Désordre. Consensus et Dissensions. Paris: Economica.

BOURDIEU, P. 1979. La Distinction. Critique Sociale du Jugement. Paris: Minuit.

. 1989. La N oblesse d'État. Grandes Écoles et Esprit de Corps. Paris: Minuit.

. 1992. Réponses. Pour une Anthropologie Réflexive. Paris: Seuil.

CARO, J.-Y. 1983. Les Économistes Distingués. Logique Sociale d'un Champ Scientifique. Paris: Presses de la FNSP.

COATS, A. W. 1993. British and American Essays (vol. II - The Sociology and Professionalization of Economics). London/New York: Routledge. (dir.). 1997. The Post-1945 Internationalization of Economics. Durham: Duke University Press.

COLANDER, D. C. e COATS, A. W. (eds.). 1990. The Spread of Economic Ideas. Cambridge: Cambridge University Press.

COMBES, P. P. e LINNEMER, L. 1999. “La Publication d'A rticles de Recherche en Économie en France". CREST, Document de Travail, 9968.

D'AUTUME, A. e CARTELIER, J. (dir.). 1995. L'Économie Devient-elle une Science Dure? Paris: Economica.

DRAKE, Paul W. (ed.). 1993. Money Doctors, Foreign Debts and Economic Reforms in Latin America from the 1890s to the Present. J aguar Books.
DUVAL, J . et alii. 1998. Le “Décembre" des Intellectuels Français. Paris: Liber/Raisons d'Agir.

FREY, B. e EICHENBERGER, R. 1992. “Economics' and Economists: A European Perspective". A merican Economic Review, 82(2):216-220.

FUCHS, V. R. et alii. 1998. "Economists Views about Parameters, $V$ alues and Policies: Survey Results in Labor and Public Economics". J ournal of Economic Literature, XXXVI: 13871425.

HALL, P. (ed.). 1989. The Political Power of Economic Ideas. Keynesianism across Nations. Cambridge, MA: Harvard University Press.

J OBERT, B. e THÉRET, B. 1994. “France: La Consécration Républicaine du Néo-libéralisme". In: B. J obert (dir.), Le Tournant Néo-libéral en Europe. Paris: L'Harmattan.

KELSEY, J. 1995. Economic Fundamentalism London, East Heaven, CT: Pluto Press.

KLAMER, A. e COLANDER, D. 1990. The Making of an Economist. Boulder: Westview Press.

LEBARON, F. 1996. Les Économistes Français entre Science et Politique. Contribution à une Sociologie de la Culture Économique. Tese de Doutorado da EHESS. . 1997. “La Dénégation du Pouvoir. Le Champ des Économistes Français au Milieu des Années 1990". 
Actes de la Recherche en Sciences Sociales, 119.

MALINVAUD, E. 1996. “Pourquoi les Économistes ne Font pas de Découverte". Revue d'Économie Politique, 106(6).

ROUANET, H. e LE ROUX, B. 1993. Analyse des Données Multidimensionnelles. Paris: Dunod.

ROUX, D. e SOULIÉ, D. 1991. Les Prix Nobel de Sciences Économiques 1969-1990. Paris: Economica.

SHAPIN, S. e SHAFFER, S. 1993. Leviathan et la Pompe à Air. Hobbes et Boyle entre Science et Politique. Paris: La Découverte.

SIMIAND, F. 1932. Le Salaire, I'Évolution Sociale et la Monnaie. Paris: Félix Alcan.

WEILLER, J. e CARRIER, B. 1994. L'Économie Non-conformiste en France au XX Siècle. Paris: PUF.

WHITLEY, R. 1984. The Intellectual and Social Organization of the Sciences. London/New York: Oxford University Press. 
Resumo

A noção de economista, longe de simples e evidente, é objeto de numerosas lutas de definição. $O$ exemplo do campo dos economistas franceses, analisado a partir de um conjunto de entrevistas, observações de dados prosopográficos, revela certas características dessas lutas. Estas opõem detendores de formas diferenciadas de capital, que estão elas mesmas em correspondência com posições distintas no campo do poder. N essas lutas, estão em questão ao mesmo tempo a autonomia e a estrutura desse campo científico. A fraca autonomia relativa do campo da ciência econômica se faz acompanhar de uma forte homologia entre a estrutura desse campo e aquela do campo do poder francês em seu conjunto.

Palavras-chave Economistas, Ciência Econômica, Campo Científico, Autonomia, Lutas Simbólicas

\section{Abstract}

The concept of the economist, rather than being a simple and evident one, is the object of numerous conflicting definitions. The example of the field of French economists, as analysed in a set of interviews and the observation of prospographical data, reveal certain characteristics of these conflicts. These struggles oppose those who detain differentiated forms of capital, which are themselves in correspondence with distinct positions in the field of power. These conflicts put into question both the autonomy and the structure of this scientific field. The relatively weak autonomy of the field of economical sciences is followed by a strong homology between the structure of this field and that of the field of French power in its entirety.

Key words Economists, Economic Science, Scientific Field, Autonomy, Symbolic Struggles 